\title{
Competition, Technological Change and Productivity Gains: A Sectoral Analysis
}

The empirical relationship between competition intensity and the rate of productivity growth across 30 sectors of the French economy between 1978 and 2015 displays an inverted U-shape. This implies that there exists an optimal level of competition for each sector, defined by the price markup that maximises the growth rate of hourly labour productivity. As there is a significant and strong positive correlation between optimal markups and technical progress rates in each sector, it follows that sectors with high technical progress require higher markups to maximise their labour productivity growth rate. The persistence of non-optimal markups in French sectors is associated with a $0.4 \%$ loss in aggregate annual labour productivity growth during the period (1.86\%). French long-term productivity growth could have reached $2.25 \%$ had markups been at their optimal level. As a result, policies to foster innovation and productivity should aim at enabling the optimal level of markup (or market power), particularly in high-innovation sectors.

Recent research has produced evidence that the relationship between competition intensity and innovation is nonlinear and depends upon the characteristics of markets and sectors (Aghion et al., 2013; Schmutzler, 2013). An increase in competition intensity (equivalently, a lower markup over marginal cost or over the perfect competition price) $)^{1}$ can lead to diverging effects on innovation. In line with the prediction that competition above a certain level can discourage innovation (Aghion et al., 2005; Bouis and Klein, 2008), we first show that in the French economy (30 sectors observed) over the period 1978-2015, markups and hourly labour productivity growth exhibit an inverted $U$-shaped relationship. We then estimate the sector-specific markup thresholds beyond which any further increase

(C) The Author(s) 2020. Open Access: This article is distributed under the terms of the Creative Commons Attribution 4.0 International License (https://creativecommons.org/licenses/by/4.0/).

Open Access funding provided by ZBW - Leibniz Information Centre for Economics.

* The views expressed do not necessarily reflect those of the institutions with which the authors are affiliated.

1 The markup also reflects market power, as the ability of a firm to set a price above its marginal cost. It represents the difference between prices under imperfect and perfect competition. A higher markup implies lower competition intensity. Conversely, a lower markup implies higher competition intensity.

Stéphane Ciriani, Orange, Paris, France.

François Jeanjean, Orange, Paris, France. in competition intensity harms labour productivity growth. These optimal markups are strongly correlated with the sector rate of technical progress and maximise the growth rate of labour productivity in each sector. Sectors with higher rates of technical progress thus have higher optimal markups. Such sectors necessitate sufficiently high markups to maximise their labour productivity growth. A long-term disconnect between actual and optimal sector markups would be detrimental to aggregate labour productivity growth. Some sectors, such as digital sectors, are more conducive to technical progress than others and require higher investment and hence a higher markup to maximise their labour productivity growth.

\section{Estimation strategy}

The estimation strategy to demonstrate that the empirical relationship between competition (markups) and the rate of labour productivity growth is specific to each sector and can be represented by an inverted U-shaped curve is as follows: first, actual sector markups are estimated following the methodology of Roeger (1995). Second, a nonparametric identification of the relationship between markups and labour productivity growth rates provides evidence of an inverted U-shape when sectors are grouped according to their rate of technical progress. Third, we estimate an econometric model showing that the inverted $U$ relationship between competition and productivity growth is significant. ${ }^{2}$ This allows the calcula-

2 We use a quadratic specification in which the parameters depend on each sector. 
tion of the markup that maximises the inverted $U$ curve for each sector (the optimal markups). Fourth, a strong positive and significant correlation between the optimal markups and the technical progress rates in each sector is evidenced based on our own computation of the average level of Hicks-neutral technical progress for each sector. ${ }^{3}$ This result suggests that a sector with a higher technical progress rate requires a higher optimal markup to maximise its own rate of labour productivity growth. Finally, the correlation between technical progress and optimal markups is used to estimate the losses in productivity growth due to unsuitable markups in each sector during the whole period.

Data sample: 30 sectors of the French economy observed during 1978-2015

The OECD database for structural analysis (STAN database) and the French national accounts system (INSEE) are used to analyse 30 sectors of the French economy (manufacturing, energy, construction, market services and public administration) over the period 1978-2015. ${ }^{4}$ The markups are estimated for each of the 30 sectors for seven periods with an average five-year duration, which provides 210 estimated markups. Seven periods are considered: the 1st period (1978-1984), the 2nd period (1985$1989)$, the 3rd period (1990-1994), the 4th period (1995$1999)$, the 5th period (2000-2004), the 6th period (20052009) and the 7th period (2010-2015). Each period's duration derives from a trade-off between the accuracy of the markup estimations and the number of periods that provides the largest number of observations. Indeed, longer periods improve the accuracy of markup estimations but reduce the number of periods and thus, the number of observations. The compound annual growth rate of hourly labour productivity is computed for each of the seven periods.

\section{A nonparametric identification of the markup and labour productivity growth rate relationship}

As a first approach, the relationship between competition and productivity growth can be represented by a scatter plot of the sector markups and the compound annual growth rate of hourly labour productivity during the seven periods running from 1978 to 2015 (Figure 1). The scatter plot shows 210 points (30 sectors observed during the

3 The Hicks-neutral technical progress is derived from the markupadjusted Solow residual following the methodology applied in Roeger (1995). This methodology is also applied in Bouis and Klein (2008).

4 The price deflator for gross fixed capital formation for the French economy and the real long-term interest rate, which are used to compute the cost of capital, are retrieved from the AMECO database of the European Commission.
Figure 1

Hourly labour productivity growth and markups by sector

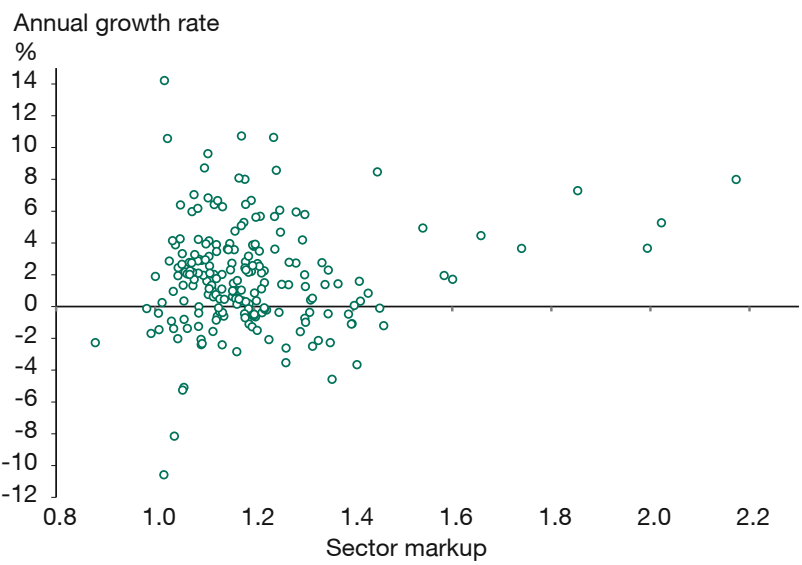

Source: Authors' own elaboration.

seven periods), and each point on the figure represents a sector observed during each of the seven specific periods.

At first glance, the scatter plot does not provide any obvious or robust result regarding the link between competition and productivity growth. However, by grouping sectors according to their level of technical progress, it appears that an inverted $U$-shaped relationship actually characterises the effect of markups on the rate of hourly labour productivity growth (Figure 2). This graph suggests that the relationship between competition intensity and labour productivity growth may vary across sectors subject to their specific rate of technical progress. Hence, markups over marginal costs or perfect competition prices could be related to sector-specific characteristics, meaning that higher markups do not necessarily imply the existence of static monopoly rents.

Figure 2 provides a scatter plot of four smoothed moving averages. Each curve represents a set of sectors grouped according to their technical progress rate. The smoothed moving average is computed as follows: a point defined by markup $x_{i}$ and annual productivity growth $y_{i}$, denoted $\left(x_{i}, y_{i}\right)$, is shifted to point $\left(X_{i}, Y_{j}\right)$ following:

$$
X_{i}=\frac{1}{2 b+1} \sum_{j=i-b}^{i+b} x_{j} \text { and } Y_{i}=\frac{1}{2 b+1} \sum_{j=i-b}^{i+b} y_{j}
$$

with $(i, j) \in\{1, \ldots, n\}$, where $n$ is the number of observations of a set of sectors and $b$ is the bandwidth of the smoothing. We use $n=42$ for the three sets with the highest rate of technical progress ('High technical progress', 'Medium-high technical progress' and 'Mediumlow technical progress') and $n=84$ for the 'Low techni- 


\section{Figure 2}

Relationship between hourly labour productivity growth and markup according to the level of technical progress

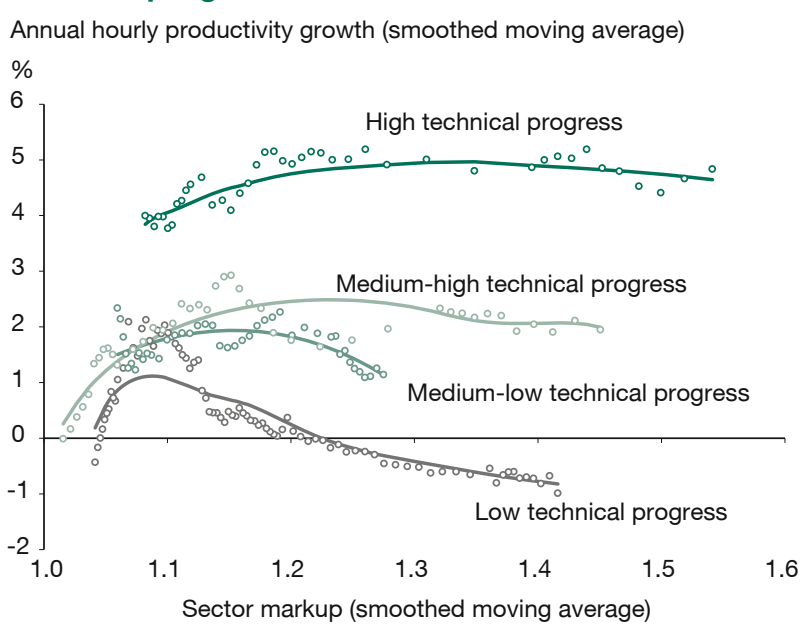

Note: 'High technical progress' set groups together sectors with a technical progress rate higher than 2.5\%; 'Medium-high technical progress' set groups sectors with a rate between $2.5 \%$ and $1.86 \%$; the 'Medium-low technical progress' set groups sectors with a rate between $1.86 \%$ and $1.5 \%$; and the 'Low technical progress' set groups sectors with a rate lower than $1.5 \%$

Source: Authors' own elaboration.

cal progress' set. ${ }^{5}$ The smoothing of the moving averages reduces the volatility of the observations and reveals the trends of the effects of markups on productivity growth. Each smoothed moving average exhibits an inverted Ushape with a peak corresponding to a higher markup for higher technical progress. Indeed, the peak of the 'Low technical progress' set is reached for a markup close to 1.10; the peak of the 'Medium-low technical progress' set is reached for a markup close to 1.15; the peak of the 'Medium-high technical progress' set is reached for a markup close to 1.24; and the peak of the 'High technical progress' set is reached for a markup close to 1.34. This result suggests that an increase in the rate of technical progress in turn increases the markup level that maximises the hourly productivity growth of the sector.

\section{Estimation of optimal sector markups}

The optimal levels of markup in each of the 30 sectors are obtained by estimating an econometric model based on a quadratic function. This specification allows for the estimation of the effect of variations in the markups on the rate of labour productivity growth for each sector. A dum-

5 Six sectors are represented in the three first sets and 12 sectors in the fourth set, as in the fourth set the differences among sectors are not sufficient to distinguish them into two subsets. my variable is associated with the squared markup term, which allows the estimated coefficient to vary across sectors. The following Equation (1)

$$
\text { CAGRprod }_{i p}=c+\alpha_{i} d_{i} \text { markup }_{i p}^{2}+\beta \text { markup }_{i p}+\operatorname{intbub}+\lambda d_{p}+\varepsilon_{i p}
$$

is estimated where $i \in\{1,2, \ldots, 30\}$ is the index of the sector, $p \in\{1,2, \ldots, 7\}$ is the index of the period, CAGRprod ${ }_{i p}$ is the compound annual growth rate of production at current prices of sector $i$, markup ${ }_{i p}$ is the estimated markup for sector $i$ and $i n t b u b$ is a dummy variable that captures the impact of the Internet bubble, which might have affected the information technology sectors during the fifth period (2000-2004). During the fifth period, intbub $=1$ (intbub $=$ 0 otherwise) for each sector in the information technology category, which includes 'Computer, electronic and optical products', 'Publishing, audio-visual and broadcasting activities', and 'Telecommunications; IT and other information services'. In this equation, the individual (sector) fixed effects have been removed to avoid interactions with the dummy indicator. The term $d_{i}$ represents the dummy indicator of sector $i, d_{p}$ is a period fixed effect, $\beta$ is the coefficient of the markup that is common to all sectors, $\alpha_{i}$ is the coefficient of the squared markup specific to sector $i$, $c$ is a constant and $\varepsilon_{i p}$ is the residual. The optimal markup for sector $i$ is then determined by the following term:

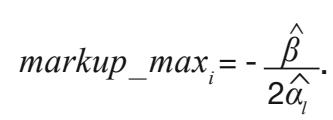

As a result, the corresponding maximum level of hourly productivity growth is defined by

$$
\text { CAGRprod_max } x_{i}=\hat{c}-\frac{\hat{\beta}^{2}}{4 \hat{\alpha_{l}}} .
$$

The results of the estimation are presented in Table 1. The first column provides the explanatory variables; the second column provides the estimated coefficients of Equation (1) with detailed sector-specific squared markups; the third column provides the associated standard error; the fourth column provides the optimal markup for each sector, calculated on the basis of the estimated markup coefficients; the fifth column provides the associated standard error; the sixth column provides the annual average growth rate of maximised labour productivity; and the last column provides the associated standard error. The values of the fourth and sixth columns are calculated with the 'delta method'. The estimated coefficient of the markup term is significant. The estimated coefficients of the squared markup terms are significant for all sectors, with the exception of a single sector for which the coefficient is nevertheless close to the $10 \%$ significance threshold. The estimated coefficients of the optimal markups are 
Table 1

\section{Estimations result: Markup and hourly labour productivity growth}

\begin{tabular}{|c|c|c|c|c|c|c|}
\hline $\begin{array}{l}\text { Dependent variable: Hourly productivity growth } \\
\text { Explanatory variables }\end{array}$ & $\begin{array}{l}\text { CAGRprod } \\
\text { coeff. }\end{array}$ & $\begin{array}{l}\text { Standard } \\
\text { error }\end{array}$ & markup $_{\max }$ & $\begin{array}{l}\text { Standard } \\
\text { error }\end{array}$ & CAPRprod $_{\max }$ & $\begin{array}{l}\text { Standard } \\
\text { error }\end{array}$ \\
\hline $\begin{array}{l}\text { markup } \\
\text { markup }{ }^{2}\end{array}$ & $0.2428^{\star *}$ & $(0.0962)$ & & & & \\
\hline \multicolumn{7}{|l|}{ Sector (OECD code) } \\
\hline D05T09 Mining and quarrying & $-0.1051^{\star \star \star}$ & $(0.0375)$ & $1.1546^{\star \star \star}$ & $(0.1308)$ & 0.0003 & $(0.0095)$ \\
\hline D10T12 Food products, beverages and tobacco & $-0.1020^{\star \star \star}$ & $(0.0372)$ & $1.1902^{\star * \star}$ & $(0.1474)$ & 0.0046 & $(0.0046)$ \\
\hline D13T15 Textiles, wearing apparel, leather and related products & $-0.0816^{\star *}$ & $(0.0370)$ & $1.4874^{\star \star \star}$ & $(0.2697)$ & $0.0407^{\star *}$ & $(0.0205)$ \\
\hline D16T18 Wood and paper products, and printing & $-0.0836^{\star *}$ & $(0.0371)$ & $1.4521^{\star \star \star}$ & $(0.2220)$ & $0.0364^{\star \star \star}$ & $(0.0132)$ \\
\hline D19 Coke and refined petroleum products & $-0.0994^{\star \star}$ & $(0.0477)$ & $1.2211^{\star \star \star}$ & $(0.3729)$ & 0.0083 & $(0.0411)$ \\
\hline D20T21 Chemical and pharmaceutical products & $-0.0779^{\star \star}$ & $(0.0375)$ & $1.5576^{\star \star \star}$ & $(0.2424)$ & $0.0492^{\star \star \star}$ & $(0.0143)$ \\
\hline $\begin{array}{l}\text { D22T23 Rubber and plastics products, and other non-metallic mineral } \\
\text { products }\end{array}$ & $-0.0840^{\star \star}$ & $(0.0371)$ & $1.4457^{\star \star \star}$ & $(0.2043)$ & $0.0356^{\star \star \star}$ & $(0.0103)$ \\
\hline $\begin{array}{l}\text { D24T25 Basic metals and fabricated metal products, except machinery } \\
\text { and equipment }\end{array}$ & $-0.0910^{\star \star}$ & $(0.0370)$ & $1.3336^{\star \star \star}$ & $(0.1808)$ & $0.0220^{\star \star \star}$ & $(0.0079)$ \\
\hline D26 Computer, electronic and optical products & -0.0622 & $(0.0381)$ & $1.9531^{\star \star \star}$ & $(0.5329)$ & $0.1032^{\star \star \star}$ & $(0.0383)$ \\
\hline D27 Electrical equipment & $-0.0853^{\star *}$ & $(0.0384)$ & $1.4234^{\star \star \star}$ & $(0.2205)$ & $0.0329^{\star *}$ & $(0.0160)$ \\
\hline D28 Machinery and equipment & $-0.0799^{\star \star}$ & $(0.0372)$ & $1.5188^{\star \star \star}$ & $(0.2477)$ & $0.0445^{\star \star \star}$ & $(0.0159)$ \\
\hline D29T30 Transport equipment & $-0.0807^{\star *}$ & $(0.0376)$ & $1.5048^{\star \star \star}$ & $(0.2774)$ & $0.0428^{\star \star \star}$ & $(0.0219)$ \\
\hline $\begin{array}{l}\text { D31T33 Furniture; other manufacturing; repair and installation of machin- } \\
\text { ery and equipment }\end{array}$ & $-0.0770^{* *}$ & $(0.0371)$ & $1.5756^{\star \star \star}$ & $(0.2924)$ & $0.0514^{\star \star}$ & $(0.0211)$ \\
\hline D35 Electricity, gas, steam and air conditioning supply & $-0.0833^{\star \star}$ & $(0.0354)$ & $1.4578^{\star \star \star}$ & $(0.1096)$ & $0.0371^{\star \star \star}$ & $(0.0090)$ \\
\hline $\begin{array}{l}\text { D36T39 Water supply; sewerage, waste management and remediation } \\
\text { activities }\end{array}$ & $-0.1011^{\star \star \star}$ & $(0.0381)$ & $1.2006^{* * *}$ & $(0.1668)$ & 0.0059 & $(0.0156)$ \\
\hline D41T43 Construction & $-0.1057^{\star \star \star}$ & $(0.0371)$ & $1.1487^{\star \star \star}$ & $(0.1571)$ & -0.0005 & $(0.0056)$ \\
\hline $\begin{array}{l}\text { D45T47 Wholesale and retail trade, repair of motor vehicles and motorcy- } \\
\text { cles }\end{array}$ & $-0.0954^{* *}$ & $(0.0371)$ & $1.2724^{\star \star \star}$ & $(0.1483)$ & $0.0146^{\star * *}$ & $(0.0046)$ \\
\hline D49T53 Transportation and storage & $-0.0837^{\star \star}$ & $(0.0375)$ & $1.4506^{\star \star \star}$ & $(0.2184)$ & $0.0362^{* *}$ & $(0.0143)$ \\
\hline D55T56 Accommodation and food service activities & $-0.1120^{\star \star \star}$ & $(0.0371)$ & $1.0836^{\star \star \star}$ & $(0.1394)$ & $-0.0083^{*}$ & $(0.0048)$ \\
\hline D58T60 Publishing, audiovisual and broadcasting activities & $-0.1054^{\star \star \star}$ & $(0.0377)$ & $1.1515^{\star \star \star}$ & $(0.1368)$ & 0.0059 & $(0.0056)$ \\
\hline D61 Telecommunications & $-0.0691^{\star *}$ & $(0.0333)$ & $1.7579^{\star \star \star}$ & $(0.1948)$ & $0.0795^{\star \star \star}$ & $(0.0112)$ \\
\hline D62T63 IT and other information services & $-0.1096^{\star \star \star}$ & $(0.0377)$ & $1.1081^{* * *}$ & $(0.1344)$ & 0.0006 & $(0.0084)$ \\
\hline D64T66 Financial and insurance activities & $-0.0929^{\star *}$ & $(0.0373)$ & $1.3061^{\star * \star}$ & $(0.1429)$ & $0.0187^{\star \star \star}$ & $(0.0071)$ \\
\hline $\begin{array}{l}\text { D69T71 Legal and accounting activities; activities of head offices; man- } \\
\text { agement consultancy activities; architecture and engineering activities; } \\
\text { technical testing and analysis }\end{array}$ & $-0.1071^{\star \star \star}$ & $(0.0361)$ & $1.1337^{\star \star \star}$ & $(0.1839)$ & -0.0023 & $(0.0070)$ \\
\hline D72 Scientific research and development & $-0.1018^{\star \star \star}$ & $(0.0370)$ & $1.1920^{\star * *}$ & $(0.1081)$ & 0.0048 & $(0.0066)$ \\
\hline $\begin{array}{l}\text { D73T75 Advertising and market research; other professional, scientific } \\
\text { and technical activities; veterinary activities }\end{array}$ & $-0.1010^{\star \star \star}$ & $(0.0374)$ & $1.2023^{\star \star *}$ & $(0.1637)$ & 0.0061 & $(0.0088)$ \\
\hline D77T82 Administrative and support service activities & $-0.1129^{\star \star \star}$ & $(0.0372)$ & $1.0750^{\star \star \star}$ & $(0.1193)$ & -0.0094 & $(0.0072)$ \\
\hline $\begin{array}{l}\text { D84T88 Public administration and defence; compulsory social security; } \\
\text { education; human health and social work activities }\end{array}$ & $-0.1059^{\star \star \star}$ & $(0.0374)$ & $1.1460^{\star \star \star}$ & $(0.1397)$ & -0.0008 & $(0.0045)$ \\
\hline D90T93 Arts, entertainment and recreation & $-0.1059^{* \star *}$ & $(0.0396)$ & $1.1461^{* * *}$ & $(0.1541)$ & -0.0008 & $(0.0043)$ \\
\hline D94T96 Other service activities & $-0.1062^{* * *}$ & $(0.0389)$ & $1.1427^{\star \star \star}$ & $(0.1480)$ & -0.0012 & $(0.0118)$ \\
\hline intbub & $0.0421^{*}$ & $(0.0225)$ & & & & \\
\hline Period fixed effects & yes & & & & & \\
\hline Sector fixed effects & no & & & & & \\
\hline Constant & $-0.1424^{\star \star}$ & $(0.0645)$ & & & & \\
\hline$R^{2}$ & 0.487 & & & & & \\
\hline Observations & 210 & & & & & \\
\hline
\end{tabular}

Notes: Significant at $1 \%\left({ }^{* *}\right), 5 \%\left({ }^{* \star}\right)$ and $10 \%\left({ }^{*}\right)$. Robust standard errors in parentheses.

Source: Authors' own calculation. 


\section{Figure 3}

\section{Correlation between optimal markups and total} productivity growth by sector

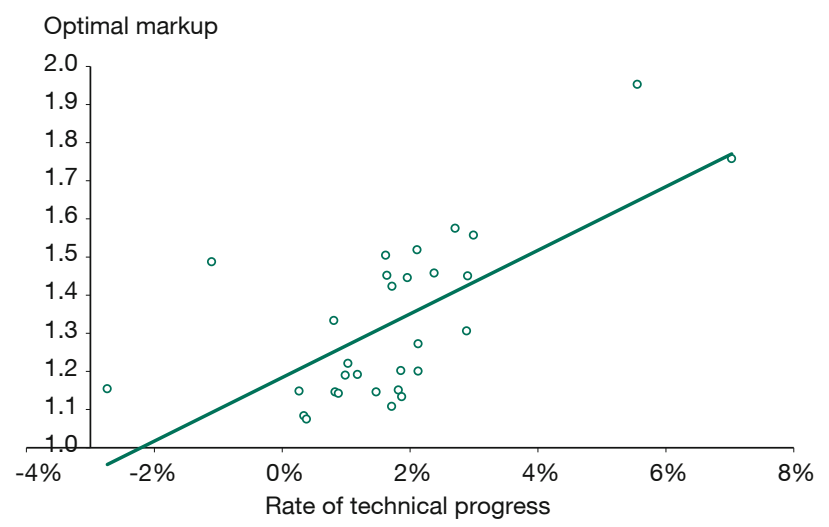

Source: Authors' own elaboration.

all highly significant. As a result, the estimates confirm a nonlinear, inverted U-shaped relationship between competition and labour productivity, which captures the actual rate at which technical progress is adopted in the economy.

The optimal markup is strongly correlated with the rate of technical progress

Figure 3 represents the correlation between the optimal markup and the average rate of technical progress (denoted $\theta g$ ) for each sector.

The line indicates the linear fit of the scatter plot. The correlation coefficient between the sector-specific optimal markup and the rates of technical progress is 0.67 , which is above the $1 \%$ significance threshold $(0.416)$, for the 30 observations. The correlation between average markups and the technical progress rate is positive but weakly significant. In other words, average markups are weakly correlated with technical progress, while the optimal markups that we calculated are strongly correlated with technical progress. Such a strong correlation suggests that sectors experiencing higher rates of technical progress require higher optimal markups to maximise their productivity growth rate.

Indeed, labour productivity growth reflects improvements in production techniques, which require investment. Markups have two contrary effects on investment. On the one hand, they tend to reduce investment, in line with the 'escape competition' effect. On the other hand, they tend to increase investment, in line with the Schumpeterian effect. The markup that maximises investment reflects an underlying trade-off between those two effects in each sector. As the productivity impact of technical progress occurs through investment, a higher rate of technical progress strengthens the Schumpeterian effect more than the 'escape competition' effect. As a result, the trade-off in a sector with a higher rate of technical progress tends to shift towards higher markups (Jeanjean, 2020).

\section{Labour productivity losses due to unsuitable markups}

In the previous section, we calculated the optimal markup for each sector. This means that when the markup is above or below this level, productivity growth is not reaching its maximum level. The gap between observed productivity growth and maximum productivity growth can be considered a productivity loss. To estimate the productivity losses for each sector in each period, it is necessary to compute, on the one hand, the difference in each period and for each sector between the actual markup and the optimal markup:

$$
\operatorname{markup}_{i p}=\text { markup }_{i p}-\text { markupmax }_{i} .
$$

On the other hand, it is necessary to compute the difference between the hourly labour productivity growth rate and the maximum labour productivity growth rate, which is simply the difference between the hourly labour productivity growth and the rate of productivity growth that is achieved when markups coincide with their optimal levels in each sector:

$$
\Delta \text { CAGRprod }_{i p}=\text { CAGRprod }_{i p}-\text { CAGRprodmax }_{i} .
$$

If markupmax $_{i}$ is the optimal markup, one can expect that the first difference $\triangle$ CAGRprod $_{i p}$ is increasing when $\Delta$ markup $_{i p}<0$ and decreasing when $\Delta$ markup $_{i p}>0$. Hence, an increase in the variation rate of markups leads to a decrease in the variation rate of labour productivity. Figure 4 presents the variations in hourly labour productivity growth as a function of the markup over perfectly competitive prices.

The scatter plot points to the impact of the difference between the actual sector markups and the optimal markups on the growth rate of labour productivity. The origin point of the graph represents the estimated optimal markup and the corresponding hourly productivity growth for each sector. An upward or downward deviation from this optimal markup results in a decrease in the rate of hourly labour productivity growth. Equation (2) allows for an estimation of the losses in productivity growth caused by unsuitable markups.

$$
\Delta \text { CAGRprod }_{i p}=c+\left|\operatorname{smarkup}_{i p}\right|+\beta \text { intbub }+\lambda d_{p}+\varepsilon_{i p}
$$

The Internet bubble may have increased productivity growth in the information technology sector during the fifth period (2000-2004) independently of the markup levels. This effect can be corrected with the dummy variable 
Figure 4

Optimal markup and maximum hourly labour productivity growth

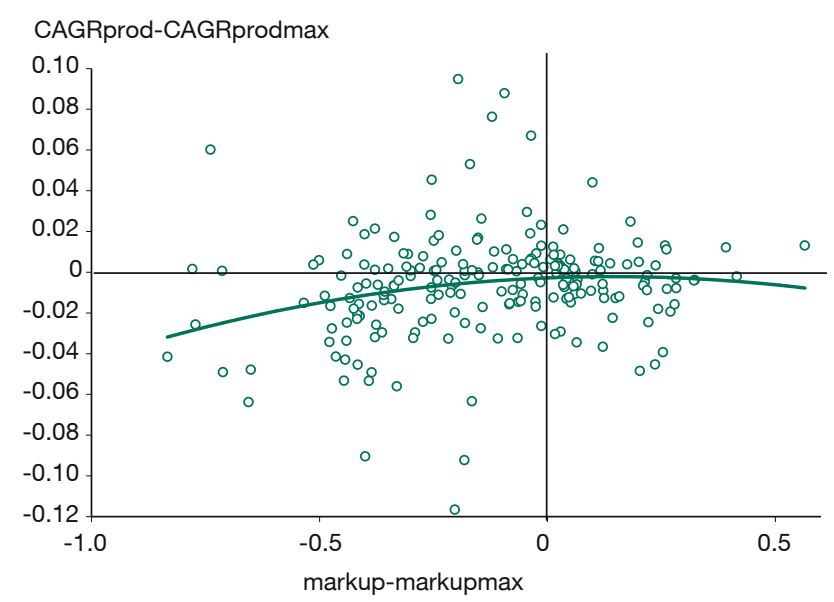

Source: Authors' own elaboration.

intbub, introduced in Equation (1). The term markup $_{i p}$ may be either positive or negative depending on the period. The absolute value of the difference between the actual and the optimal level of markup in each sector allows to analsye the impact of the distance from these sector-specific optimal markups on the growth rate of labour productivity, irrespective of the sign of the difference. The equation is estimated for first differences of the dependent variable, i.e. the hourly labour productivity growth rate.

The results are presented in Table 2, which provides ordinary least squares estimates of Equation (2). Specification (1) does not include the dummy variable that captures the effect of the Internet bubble, whereas specifications (2) and (3) include it. The coefficient of $\mid \Delta$ markup $\mid$, as expected, is negative and significant in all specifications, which confirms that hourly labour productivity growth decreases as soon as markups deviate from their estimated optimal levels. The loss of productivity growth is estimated on average at $0.373 \%$ for a deviation of 0.1 points from the optimal markup. In specifications (2) and (3), the Internet bubble dummy has a positive and significant coefficient. In summary, there exists a markup that maximises the growth rate of hourly labour productivity growth for each sector. Hence, a difference between the actual level of markups and the optimal markups in a given sector induces a divergence between the observed productivity growth rate and the maximum productivity growth rate. Figure 3 suggests that the rate of technical progress determines the potential productivity growth that could be achieved by an optimal markup, and Figure 4 shows that a deviation from this optimal markup prevents the realisation of full productivity growth.
Table 2

Check of optimal markup estimations

\begin{tabular}{|c|c|c|c|}
\hline $\begin{array}{l}\text { Dependent variable: } \\
\triangle C A G R p r o d \\
\text { Specification }\end{array}$ & (1) & (2) & (3) \\
\hline |smarkup| & $\begin{array}{l}-0.0345^{\star \star *} \\
(0.0108)\end{array}$ & $\begin{array}{c}-0.0377^{\star \star *} \\
(0.0090)\end{array}$ & $\begin{array}{c}-0.0373^{\star * *} \\
(0.0091)\end{array}$ \\
\hline intbub & & $\begin{array}{r}-0.0306^{*} \\
(0.0171)\end{array}$ & $\begin{array}{r}-0.0297^{*} \\
(0.0177)\end{array}$ \\
\hline Period fixed effects & No & No & Yes \\
\hline Constant & $\begin{array}{r}0.0013 \\
(0.0027)\end{array}$ & $\begin{array}{l}0.0014 \\
(0.002)\end{array}$ & $\begin{array}{l}0.0037 \\
(0.003)\end{array}$ \\
\hline$R^{2}$ & 0.0555 & 0.0818 & 0.1782 \\
\hline Observations & 210 & 210 & 210 \\
\hline
\end{tabular}

Notes: ${ }^{* *}$ Significant at $1 \%,{ }^{* *} 5 \%$ and ${ }^{*} 10 \%$. Robust standard errors in parentheses.

Source: Authors' own elaboration.

\section{Average annual productivity losses for each sector}

Differences between actual and optimal levels of markups entail losses in labour productivity growth. It is possible to estimate the average annual labour productivity growth that is lost due to unsuitable markup levels in each sector between 1978 and 2015. First, it is necessary to compute the mean of the differences between observed markups and optimal markups. However, as these differences may be positive in some periods and negative in others, it is necessary to compute the first differences in absolute values:

$$
\text { meansmarkup }{ }_{i}=\sum_{p=1}^{7}\left|\Delta \operatorname{markup}_{i p}\right| / 7 \text {. }
$$

Second, we calculate the mean of the differences between observed productivity growth and maximum productivity growth:

$$
\operatorname{mean} \Delta C A G R \operatorname{Rrod}_{i}=\sum_{p=1}^{7} \Delta C A \operatorname{GRprod}_{i p} / 7 .
$$

Figure 5 presents the productivity losses due to unsuitable markups. This graph shows that hourly labour productivity growth decreases when the markups deviate from their optimal levels. The correlation between the average distance from the optimal markup and the loss of productivity growth is highly significant. The coefficient of determination is $R^{2}=0.86$. The impact of the productivity loss on the global economy can be estimated by weighting each sector by its share of the global economy. 


\section{Figure 5}

\section{Productivity losses due to unsuitable markups}

Annual loss of productivity growth

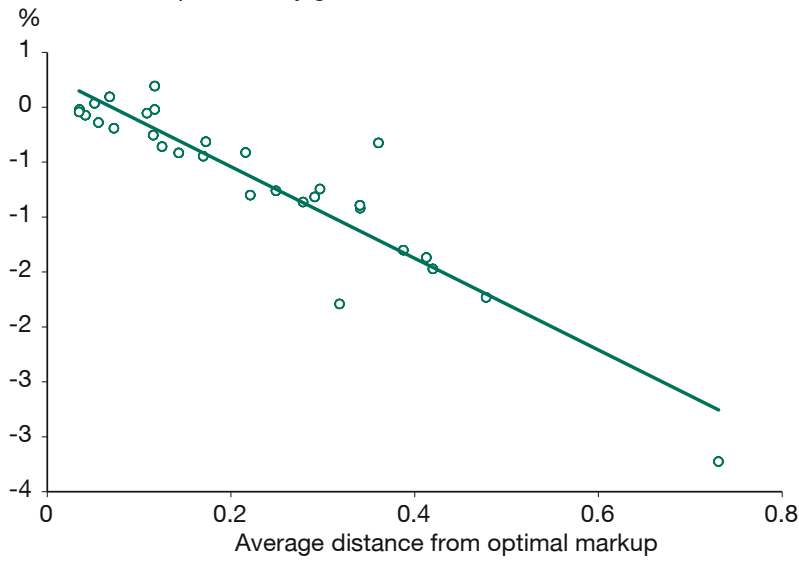

Source: Authors' own elaboration.

\section{Empirical results on productivity losses due to unsuitable markups}

The relationship between markups and the rate of labour productivity growth across 30 sectors of the French economy over the period 1978-2015 has an inverted U-shaped form, which implies that there is an optimal markup for each sector. These markups depend on the sector-specific rate of technical progress: sectors with higher rates of technical progress require higher markups to maximise their labour productivity growth. A markup that differs from its optimal level tends to reduce the growth rate of labour productivity.

The average annual loss of productivity growth due to unsuitable markups in the French economy over the period $1978-2015$ is estimated at $0.4 \%$ (with an average difference of 0.152 from the optimal markup). As the average annual growth rate of French labour productivity was $1.86 \%$ over the period, such growth could have reached $2.25 \%$ had markups been at their optimal levels.

A direct policy implication is that sectors with strong technical progress should be allowed to adjust their competition intensity to their rate of technical progress. Otherwise, they could be prevented from achieving the full productivity gains derived from the adoption of technologies. In particular, digital sectors, which have high productivity growth rates (i.e. high technical progress), require sufficiently high markups (market power) to maximise their labour productivity growth.

\section{Public policy to enhance innovation and productivity}

Public debate on competition policy is currently addressing concerns about how competition policies should adapt to the digital transformation of the economy, driven by the development of algorithms and data in all industries. Our research advocates that the assessment of competition intensity should take into account the technological progress measured in each sector. In digital sectors, specifically, the rate of innovation is high, and the trend of productivity growth is essentially driven by investment in technologies (dynamic efficiency) rather than price competition, which hinders markups above perfectly competitive prices (static efficiency; Jeanjean, 2015; Houngbonon and Jeanjean, 2016). In such sectors, higher prices do not necessarily reflect higher monopoly rents, and higher markups may reflect the expected return on risky investment in innovation (Ciriani and Lebourges, 2016).

Competition policies that aim at lowering prices to marginal costs (i.e. eliminating market power) could shift competition intensity beyond its optimal level and thus impede the expected profit margins necessary to sustain current and future investments in innovation. In sectors with a high innovation rate, investments in technologies may be curtailed due to markups below the optimal level. Moreover, reduced investment in technologies in these sectors should also have a negative impact on other sectors.

\section{References}

Aghion, P., N. Bloom, R. Blundell, R. Griffith and P. Howitt (2005), Competition and innovation: An inverted-U relationship, The Quarterly Journal of Economics, 120(2), 701-728.

Aghion, P., U. Akcigit and P. Howitt (2014), What do we learn from Schumpeterian growth theory?, in P. Aghion and S. Durlauf (eds.), Handbook of economic growth, Vol. 2, 515-563, Elsevier.

Arrow, K. J. (1962), Economic Welfare and the Allocation of Resources of Innovative Activity, in National Bureau of Economic Research, The Rate and Direction of Inventive Activity: Economic and Social Factors, 609-626, Princeton University Press.

Askenazy, P., C. Cahn and D. Irac (2013), Competition, R\&D, and the cost of innovation: evidence for France, Oxford Economic Papers, 65(2), 293-311.

Belleflamme, P. and C. Vergari (2011), Incentives to innovate in oligopolies, The Manchester School, 79(1), 6-28.

Bouis, R. and C. Klein (2008), La concurrence favorise-t-elle les gains de productivité? Analyse sectorielle dans les pays de l'OCDE, Economie et statistique, 419(1), 73-99.

Calligaris, S., C. Criscuolo and L. Marcolin (2018), Markups in the digital era, OECD Science, Technology and Industry Working Papers, 2018/10.

Houngbonon, G. V. and F. Jeanjean (2016), What level of competition intensity maximises investment in the wireless industry?, Telecommunications Policy, 40(8), 774-790.

Jeanjean, F. (2015) What causes the megabyte price drop in the mobile industry?, Economia e Politica Industriale, 42(3), 277-296.

Jeanjean, F. (2020), Impact of Technical Progress on the Relationship Between Competition and Investment, Journal of Industry, Competition and Trade.

Roeger, W. (1995), Can imperfect competition explain the difference between primal and dual productivity measures?, Estimates for US manufacturing, Journal of Political Economy, 103(2),316-330.

Schmutzler, A. (2013), Competition and investment: A unified approach, International Journal of Industrial Organization, 31(5), 477-487.

Schumpeter, J. (1942), Creative destruction, Capitalism, socialism and democracy, 825, 82-85. 